\title{
Plasma Vitamin C Concentration is Not Related to the Incidence of Ketosis in Dairy Cows during the Early Lactation Period
}

\author{
Licza PADILLA ${ }^{1)}$, Ken-ichi SHIBANO ${ }^{2)}$, Jun INOUE ${ }^{2)}$, Tohru MATSUI ${ }^{1)}$ and Hideo YANO ${ }^{1)}$ \\ ${ }^{1)}$ Division of Applied Biosciences, Graduate School of Agriculture, Kyoto University, Sakyo-ku, Kyoto 606-8502, ${ }^{2)}$ Hyogo Prefectural \\ Federation of Agricultural Mutual Aid Association, Kobe, Hyogo 651-1343, Japan
}

(Received 25 November 2004/Accepted 20 May 2005)

\begin{abstract}
Many animals including cattle can synthesize vitamin C from glucose. The objective of this study was to investigate plasma vitamin $\mathrm{C}$ concentration in ketotic cows during the early lactation period because glucose supply for vitamin $\mathrm{C}$ synthesis might be limited in these cows. We measured plasma $\beta$-hydroxybutyrate (BHBA) concentration in 118 cows within 2 months after parturition. Subclinical/clinical ketosis was quantitatively determined using a plasma BHBA threshold of 1,200 $\mu \mathrm{M}$. Plasma glucose concentration was lower in the ketotic cows than in the control cows but plasma vitamin $\mathrm{C}$ concentration did not differ between the control and the ketotic cows. Then we measured plasma vitamin C, BHBA and glucose levels in 7 cows during the periparturient period. Plasma BHBA increased and plasma glucose decreased after parturition but plasma vitamin $\mathrm{C}$ did not change. These results indicate that plasma vitamin $\mathrm{C}$ is not related to the incidence of ketosis in the early lactation period. We suggest that ketotic cows have the ability to produce vitamin $\mathrm{C}$ to meet its requirement in the early lactation period although glucose supply is not sufficient for milk production. Vitamin $\mathrm{C}$ synthesis is possibly given a high metabolic-priority for glucose in lactating cows.

KEY WORDS: dairy cow, $\beta$-hydroxybutyrate, ketosis, vitamin C.
\end{abstract}

J. Vet. Med. Sci. 67(9): 883-886, 2005

Domestic animals have not been considered to require dietary vitamin $\mathrm{C}$ because they can synthesize a sufficient amount of ascorbic acid (AsA) in the liver [11]. However, a clinical case of scurvy that is a typical sign of vitamin $\mathrm{C}$ deficiency was reported in cows [7]. The supplementation with vitamin $\mathrm{C}$ improved antibody response to an antigen in the calves that had low plasma $\mathrm{C}$ concentration [5]. Plasma vitamin $\mathrm{C}$ concentration decreased in the calves stressed by housing condition [6]. A recent study indicated that plasma vitamin $\mathrm{C}$ level was decreased after the induction of mastitis in lactating cows [19]. Furthermore, vitamin $\mathrm{C}$ administration stimulated recovery from acute mammary inflammation in dairy cattle [4]. These reports suggested that stressed cattle possibly suffered from vitamin $\mathrm{C}$ deficiency.

The supply of vitamin $\mathrm{C}$ for ruminants mostly depends on AsA synthesis from glucose since dietary vitamin $\mathrm{C}$ is easily degraded in the rumen [12]. Thus ruminants may be more prone to vitamin $\mathrm{C}$ deficiency than other domestic animals when AsA synthesis is impaired [11]. The rapid increase in milk production coupled with a limited appetite results in a negative energy balance in the early lactation period and cows are unable to synthesize sufficient glucose. Thus, lactating cows were considered to have a decreased synthesis of AsA resulting from the shortage of glucose, especially in the early lactation period [10]. On the other hand, Santos et al. [14] reported that plasma vitamin $\mathrm{C}$ concentration was not affected by the stage of lactation and they suggested that endogenous AsA production met vitamin $\mathrm{C}$ requirement for lactating cows.

\footnotetext{
* Correspondence to: Matsui, T., Division of Applied Biosciences, Graduate School of Agriculture, Kyoto University, Sakyo-ku, Kyoto, 606-8502, Japan.
}

Ketosis is a disease related to the high rate of glucose utilization in the mammary gland and the inability of the cows to meet the glucose demand through its supply [2]. Thus ketosis is frequently observed in dairy cows during the early lactation period. The stage of lactation did not affect plasma $\beta$-hydroxybutyrate (BHBA) concentration and the level of BHBA did not differ between dry cows and lactating cows in the report of Santos et al. [14]. Therefore, their cows were not considered to have a marked imbalance between glucose supply and glucose requirement in the early lactation period, which might result in stable AsA level in plasma. Plasma vitamin $\mathrm{C}$ concentration may be related to the incidence of ketosis in dairy cows during early lactation period because glucose shortage induces ketosis and possibly lowers plasma vitamin $\mathrm{C}$ through decreasing its synthesis. We investigated the relationship between plasma vitamin $\mathrm{C}$ and BHBA in cows during early lactation period.

\section{MATERIALS AND METHODS}

Animals and sample collection: We used 118 lactating Holstein cows raised in dairy farms in experiment 1 . These animals consisted of cows diagnosed as ketotic and control cows in the same herds. Blood sample was collected from the jugular vein into heparinized tube within 2 months after parturition. In experiment 2, we used multiparous Holstein cows that were raised in a dairy farm. Seven cows were given the diet that mainly consisted of alfalfa hay, timothy hay, sudangrass hay, a commercial concentrate ration containing trace minerals and vitamins (Rokko premium, Nishinihon Kumiai Shiryou, Kobe, Japan), and calcium phosphate (Calace 5P, Mercian, Tokyo, Japan). Composition of diet was shown in Table 1. Blood samples were col- 
Table 1. Composition of diet ${ }^{a}$

\begin{tabular}{lcc}
\hline & Dry & Lactation \\
\hline Crude protein (\%) & $\left.13.9^{\mathrm{b}}\right)$ & 15.7 \\
Digestible energy (MJ/kg) & 11.6 & 11.9 \\
Acid detergent fiber (\%) & 34.8 & 25.3 \\
Calcium (\%) & 0.5 & 0.6 \\
Phosphorus (\%) & 0.3 & 0.4 \\
\hline
\end{tabular}

a) Calculated from Standard Tables of Feed Composition in Japan [1].

b) Values were expressed as dry matter basis.

lected from the jugular vein into heparinized tubes between 1 week before, and 1, 2, 3, 4, 6 and 8 weeks after parturition. Milk yield and feed intake were not recorded.

Sample preparation and chemical analyses: The majority of vitamin $\mathrm{C}$ exists as AsA in the body of animals and AsA is reversibly oxidized to dehydroascorbic acid [11]. Therefore the sum of ASA and dehydroascorbic acid shows vitamin $\mathrm{C}$ status in the body. We prepared plasma samples and determined vitamin $\mathrm{C}$ (AsA + dehydroascorbic acid) by the method of Haiying et al. [9]. Briefly, blood samples were stored on ice and centrifuged at $4^{\circ} \mathrm{C}$ at $3,000 \mathrm{rpm}$. Heparinized plasma sample was treated with a reducing reagent, dithioerythritol at $50 \mathrm{mM}$ and kept at $-20^{\circ} \mathrm{C}$ until vitamin $\mathrm{C}$ analysis. Plasma vitamin $\mathrm{C}$ level was analyzed by the following method within 3 days after sample collection. The samples were diluted threefold with ice-cold $6.5 \mathrm{mM}$ dithioerythritol in methanol, mixed and centrifuged at 10,000 rpm for $5 \mathrm{~min}$ at $4^{\circ} \mathrm{C}$. Each supernatant was passed through a $0.45 \mu \mathrm{m}$ filter. A HPLC system consisted of a spectrophotometric detector and a reverse phase HPLC column (ODS120T, $4.6 \times 150 \mathrm{~mm}$, Tosoh, Tokyo, Japan). The mobile phase was $1 \mathrm{mM}$ ammonium formate, $7 \mathrm{mM}$ dodecyltrimethylammonium bromide and 40\% methanol (taken to $\mathrm{pH} 5.2$ with formic acid). Elution was isocratic at a flow rate of 0.9 $\mathrm{ml} / \mathrm{min}$ and the eluent was monitored at $265 \mathrm{~nm}$ to measure AsA. We previously confirmed that the treatment with dithioerythritol completely converted dehydroascorbic acid to AsA and stabilized AsA in plasma samples for 1 week at $-20^{\circ} \mathrm{C}[9]$.

Glucose and BHBA concentrations in plasma without dithioerythritol treatment were determined with an autoanalyzer (TBA-40FR, Toshiba, Tokyo, Japan) using commercial kits (Glucose, Glu Auto TBA, Denka Seiken, Tokyo, Japan; BHBA, Keton Test B, Sanwa Chemical, Nagoya, Japan).

Statistical analyses: Dairy cows were categorized into control and subclinically/clinically ketotic groups using a plasma BHBA threshold of 1,200 $\mu \mathrm{M}$ [8] in experiment 1 . The difference of plasma vitamin C, BHBA and glucose levels between groups was analyzed by an ANOVA using GLM procedure of SAS [16]. The changes in plasma BHBA, glucose and vitamin $\mathrm{C}$ concentration during periparturient period were analyzed by MIXED procedure of SAS [17] for a repeated measures design in experiment 2. The model included the repeated fixed effect of sampling time.
When the effect was significant $(\mathrm{P}<0.05)$, the PDIFF option (a pairwise t-test) was used to identify means that differed at $\mathrm{P}<0.05$. Data were expressed as means $\pm \mathrm{SE}$.

\section{RESULTS}

We used 118 lactating dairy cows within 2 months after parturition in experiment 1 . Twenty-seven cows were categorized as subclinically/clinically ketotic cows (Table 2). Plasma glucose level was significantly lower $(\mathrm{P}<0.05)$ in the ketotic group than in the control group. However, plasma vitamin $\mathrm{C}$ concentration did not differ between the ketotic cows and the control cows.

Then we determined plasma vitamin C, BHBA and glucose concentration in dairy cows during periparturient period in experiment 2. Plasma BHBA was significantly increased $(\mathrm{P}<0.05) 1$ week after parturition, the high level of BHBA continued to 4 weeks after parturition and then plasma BHBA recovered to the preparturient level (Fig. 1a). Plasma glucose significantly $(\mathrm{P}<0.05)$ decreased after parturition and then gradually increased but glucose level at the end of experiment was still lower $(\mathrm{P}<0.05)$ than the preparturient level (Fig. 1b). On the other hand, plasma vitamin $\mathrm{C}$ did not significantly change during the experiment (Fig. 1c). Three cows showed subclinical/clinical ketosis after parturition but plasma vitamin $\mathrm{C}$ did not decrease in these cows even when they had high BHBA concentrations.

\section{DISCUSSION}

Plasma glucose concentration was lower in the ketotic cows than in the control cows (experiment 1). These results suggested the insufficient glucose supply in the ketotic cows. Plasma vitamin $\mathrm{C}$ concentration did not differ between the ketotic and the control cows, which suggested that plasma vitamin $\mathrm{C}$ level was not low in the ketotic cows during the early lactation period. Weiss [18] reported almost similar plasma vitamin $\mathrm{C}$ levels in the lactating cows as the present experiment. Plasma vitamin $\mathrm{C}$ levels in calves showed great individual differences with variations related to genetic background [13]. We also reported a large individual difference of plasma vitamin $\mathrm{C}$ levels in beef cattle [9]. The large individual difference of plasma vitamin $\mathrm{C}$ might mask the relationship between plasma vitamin $\mathrm{C}$ and

Table 2. Plasma vitamin C, $\beta$-hydroxybutyrate (BHBA) and glucose concentrations in subclinically/clinically ketotic cows during early lactation period

\begin{tabular}{lcc}
\hline & Control cows & Ketotic cows $^{\text {a) }}$ \\
\hline Number of animals & 89 & 29 \\
BHBA $(\mu \mathrm{M})$ & $741 \pm 58$ & $2786 \pm 284^{*}$ \\
Glucose $(\mathrm{mM})$ & $3.38 \pm 0.06$ & $2.73 \pm 0.12^{*}$ \\
Vitamin $\mathrm{C}(\mu \mathrm{M})$ & $16.4 \pm 0.7$ & $16.1 \pm 0.9$ \\
\hline
\end{tabular}

Mean \pm SE

a) Subclinical/clinical ketosis was quantitatively determined using a plasma BHBA threshold of $1,200 \mu \mathrm{M}$.

* Significantly $(\mathrm{P}<0.05)$ different from control cows. 

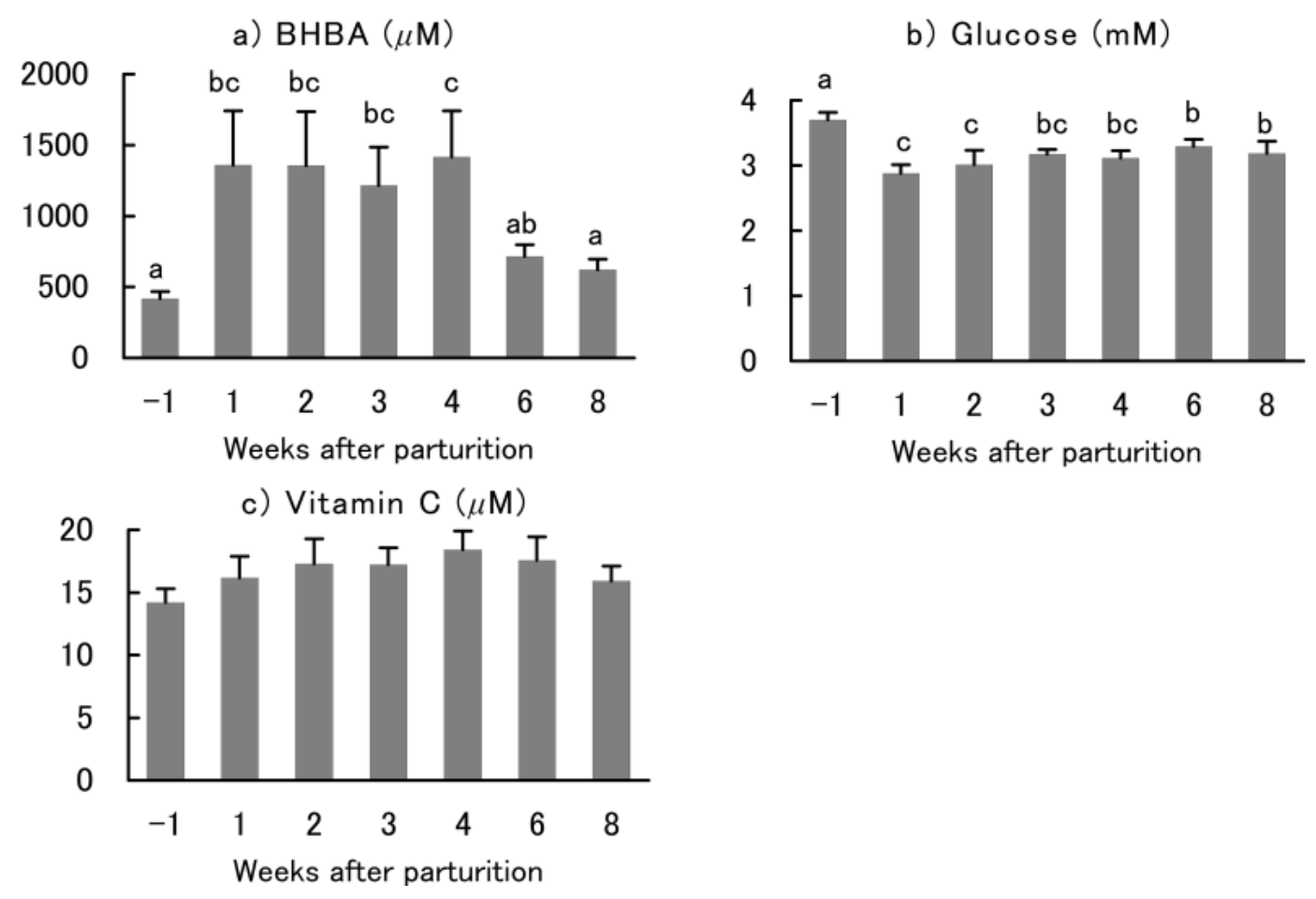

Fig. 1. Changes in plasma $\beta$-hydroxybutyrate (BHBA), glucose and vitamin $\mathrm{C}$ concentrations in dairy cows during periparturient period. Mean \pm SE for 7 cows. abc, The different superscripts showed significant difference $(\mathrm{P}<0.05)$.

\section{BHBA.}

Plasma BHBA increased and plasma glucose decreased after parturition, which suggested that cows were unable to synthesize sufficient glucose (experiment 2). On the other hand, plasma vitamin $\mathrm{C}$ concentration did not change during the periparturient period. Santos et al. [14] reported that plasma vitamin $\mathrm{C}$ concentration was not affected by stage of lactation, which was partly supported by the present experiment. However, the stage of lactation did not affect plasma BHBA concentration in their experiment. Therefore, their cows were not considered to have a marked imbalance between glucose supply and glucose demand because the shortage of glucose increased plasma BHBA concentration [2]. On the other hand, the present experiment showed that plasma vitamin $\mathrm{C}$ concentration was not low in the ketotic cows, which suggested that the ketotic cows had the ability to produce AsA to meet its requirement in the early lactation period though glucose supply was not sufficient for milk production.

There has been very few information on the control of AsA synthesis. Braun et al. [3] reported that the synthesis of AsA was increased in mice hepatocytes when glycogen breakdown was stimulated by glucagon but that glycogendepleted cells given glucose did not respond to glucagon. The biosynthetic pathway for AsA starts UDP-glucose production from glucose-1-phosphate in the liver. Therefore, they suggest that the supply of glucose-1-phosphate from glycogen breakdown must provide UDP-glucose for AsA synthesis. Plasma glucagon concentration increased and hepatic glycogen breakdown was stimulated after parturition in the ketotic cows [15]. Therefore, the substrate, i.e., glucose-1-phosphate, can be sufficiently supplied for AsA synthesis in the liver of ketotic cows after parturition. We consider that AsA synthesis is given a high metabolic-priority for glucose in these cows.

\section{REFERENCES}

1. Agriculture, Forestry and Fisheries Research Council Secretariat 2001. Standard Tables of Feed Composition in Japan, Japan Livestock Industry Association, Tokyo.

2. Baird, G. D. 1982. Primary ketosis in the high-producing dairy cow: clinical and subclinical disorders, treatment, prevention, and outlook. J. Dairy Sci. 65: 1-10.

3. Braun, L., Garzo, T., Mandl, J. and Banhegyi, G. 1994. Ascorbic acid synthesis is stimulated by enhanced glycogenolysis in murine liver. FEBS Lett. 352: 4-6.

4. Chaiyotwittayakun, A., Erskine, R. J., Bartlett, P. C., Herd, T. H., Sears, P. M. and Harmont, R.J. 2002. The effect of ascorbic acid and L-histidine therapy on acute mammary inflammation in dairy cattle. J. Dairy Sci. 85: 60-67.

5. Cummins, K. A. and Brunner, C.J. 1989. Dietary ascorbic acid and immune response in dairy calves. J. Dairy Sci. 72: 129134.

6. Cummins, K. A. and Brunner, C. J. 1991. Effect of calf housing on plasma ascorbate and endocrine and immune function. J. Dairy Sci. 74: 1582-1588.

7. Duncan, C. W., Huffman, C. F., Mitchell, R. Jr and Reid, J. T. 
1944. Symptom of scurvy observed in a herd of cattle. J. Dairy Sci. 24: 636.

8. Green, B. L., McBride, B. W., Sandals, D., Leslie, K. E., Bagg, R. and Dick, P. 1999. The impact of a monensin controlledrelease capsule on subclinical ketosis in the transition dairy cow. J. Dairy Sci. 82: 333-342.

9. Haiying, L., Padilla, L., Yoshimatsu, K., Matsui, T., Kitagawa, M. and Yano, H. 2003. Determination of plasma vitamin C concentration in fattening cattle. Anim. Sci. J. 74: 7-10.

10. Macleod, D. D., Zhang, X., Ozmeck, L. and Kennelly, J. J. 1999. Ascorbyl-3-polyphosphate as a source of ascorbic acid for dairy cattle. Milchwissenschaft 54: 123-129.

11. McDowell, L. R. 1989. Vitamins in Animal Nutrition, Academic Press, New York.

12. Nockels, C. F. 1988. Immunoenhancing vitamins for cattle. Agripractice 9: 10-17.

13. Palludan, B. and Wegger, I. 1984. Plasma ascorbic acid in calves. pp. 131-138. In: Proceedings of Ascorbic Acid in Domestic Animals (Wegger, I., Tagwerker, F. J. and Moustgaard, J. eds.), Agriculture Society, Copenhagen.
14. Santos, M. V., Lima, F. R., Rodrigues, P. H., Barros, S. B. and Laranja-Fonseca, L. F. 2001. Plasma ascorbate concentrations are not correlated with milk somatic cell count and metabolic profile in lactating and dry cows. J. Dairy Sci. 84: 134-139.

15. Smith, R., Hippen, A. R., Beitz, D. C. and Young, J. W. 1997. Metabolic characteristics of induced ketosis in normal and obese dairy cows. J. Dairy Sci. 80: 1569-1581.

16. Statistical Analysis Systems (SAS). 1990. SAS User's Guide. SAS Institute Inc., Cary, NC.

17. Statistical Analysis Systems (SAS). 1996. SAS/STAT software: Changes and Enhancements through Release 6.11. SAS Institute Inc., Cary, NC.

18. Weiss, W. P. 2001. Effect of dietary vitamin C on concentrations of ascorbic acid in plasma and milk. J. Dairy Sci. 84: 2302-2307.

19. Weiss, W. P., Hogan, J. S. and Smith, K. L. 2004. Changes in vitamin $\mathrm{C}$ concentrations in plasma and milk from dairy cows after an intramammary infusion of Escherichia coli. J. Dairy Sci. 87: 32-37. 